good/moderate E-resp rate was higher in switchers to a nonTNF-i $70 \%$ in TNF-i, $8.3 \%$ in nonTNF-i, $\mathrm{p}=0.006)$. In ADA+ subpopulation $(\mathrm{n}=34)$, no differences were found in clinical response at $v$-end in DAS28 (3.7 \pm 1.2 TNF-i, $3.9 \pm 1.1$ non-TNF-i, $\mathrm{p}=0.64), \triangle \mathrm{DAS} 28(0,63 \pm 1,6$ in TNF-i, $1,4 \pm 1,4$ in nonTNF-i, $\mathrm{p}=0,35)$ and good/moderate E-resp rate ( $30 \%$ in TNF-i, $91 \%$ in nonTNF-i, $p=0,703)$. In pts who changed to a 2nd TNF-i, those with ADA to 1st TNF-i had a higher good response rate than ADA- pts $(65 \%$ in $A D A+, 30 \%$ in $A D A-, p=0.07)$

\begin{tabular}{|l|c|c|c|}
\hline $\begin{array}{c}\text { Demographic } \\
\text { characteristics }\end{array}$ & $\begin{array}{c}\text { ADA+ } \\
\text { subpopulation }\end{array}$ & $\begin{array}{c}\text { ADA- } \\
\text { Subpopulation }\end{array}$ & $p$ \\
\hline Age (years) & $62,3 \pm 14,6$ & $65,7 \pm 14,9$ & 0,203 \\
\hline Sex (female) & $28(82 \%)$ & $23(88 \%)$ & 0,719 \\
\hline Smokers & $7(20,6 \%)$ & $4(26 \%)$ & 0,537 \\
\hline BMI & $26,9 \pm 8,9$ & $23,9 \pm 4,2$ & 0,39 \\
\hline Disease duration (years) & $19,3 \pm 8,05$ & $24,1 \pm 8,2$ & 0,844 \\
\hline RF + & $32(94 \%)$ & $20(77 \%)$ & 0,067 \\
\hline Anti-CCP + & $32(94 \%)$ & $22(88 \%)$ & 0,641 \\
\hline Basal CPR & $15,1 \pm 18,2$ & $20,4 \pm 21,7$ & 0,46 \\
\hline Basal ESR & $41 \pm 27,9$ & $38 \pm 20$ & 0,28 \\
\hline Basal DAS & $5,31 \pm 1,4$ & $5,51 \pm 1,3$ & 0,18 \\
\hline
\end{tabular}

Conclusions: The development of ADA to the first TNF-i entails a better response when switching to a 2nd TNF-i, with a similar efficacy to the pts who switched to a nonTNF-i. In those pts who did not develop immunogenicity to the 1st TNF-I, there is a better response when changing therapeutic target. The ADA measurement can help to select the pts who can benefit from a 2nd TNF-i

Disclosure of Interest: None declared

DOI: 10.1136/annrheumdis-2017-eular.6688

\section{FRI0187 RADIOGRAPHIC PROGRESSION BY DISEASE ACTIVITY STATES IN PATIENTS WITH RHEUMATOID ARTHRITIS TREATED WITH SB2 OR REFERENCE INFLIXIMAB}

J.S. Smolen ${ }^{1}$, J.-Y. Choe ${ }^{2}$, E. Keystone ${ }^{3}$, Y.H. Rho ${ }^{4}$, Y. Lee ${ }^{4}$, S. Lee ${ }^{4} .{ }^{1}$ Medical University of Vienna, Vienna, Austria; ${ }^{2}$ Daegu Catholic University Medical Center, Daegu, Korea, Republic Of; ${ }^{3}$ Mount Sinai Hospital, University of Toronto, Toronto, Canada; ${ }^{4}$ Samsung Bioepis Co., Ltd., Incheon, Korea, Republic Of

Background: Based on the totality of evidence, SB2 has shown to be similar with reference infliximab (INF) and has been approved as a biosimilar by the European Medical Agency. It is, however, hitherto unknown, if SB2 also shares similar structural efficacy in the different disease activity states when compared with INF.

Objectives: To evaluate the disease activity by simplified disease activity index (SDAI) and clinical disease activity index (CDAl) at weeks 14, 30 and 54 in patients with rheumatoid arthritis (RA) treated with SB2 or INF from a phase III study and to assess the radiographic progression at week 54 in patients by disease activity states (remission, low disease activity [LDA], moderate disease activity [MDA], or high disease activity [HDA]).

Methods: Patients with RA were randomised to receive either SB2 or INF 3 $\mathrm{mg} / \mathrm{kg}$ at weeks $0,2,6$, and then every 8 weeks thereafter until week 46 with background methotrexate. Dose increments were allowed after week 30 by 1.5 $\mathrm{mg} / \mathrm{kg}$ up to a maximum dose of $7.5 \mathrm{mg} / \mathrm{kg}$. Disease activities by SDAI, and CDAl were compared at weeks 14,30 , and 54 . The radiographic progression was measured by modified Total Sharp Score (mTSS) at weeks 0 and 54 .

Results: Up to week 54, comparable proportions of patients achieved ACREULAR-index remission between SB2 and INF (by SDAl: 13/279 [4.7\%] vs. $13 / 283$ [4.6\%] at week $14 ; 24 / 250$ [9.6\%] vs. 29/263 [11.0\%] at week 30; 34/226 [15.0\%] vs. $24 / 224[10.7 \%]$ at week 54 ; by CDAl: $12 / 279$ [4.3\%] vs. $12 / 283$ [4.2\%] at week $14 ; 22 / 253[8.7 \%]$ vs. $31 / 265[11.7 \%]$ at week $30 ; 33 / 227[14.5 \%]$ vs. $24 / 225[10.7 \%]$ at week 54 in SB2 and INF, respectively). The proportions of radiographic non-progressors (defined as change in mTSS $\leq 0$ ) by disease activity were comparable between SB2 and INF at week 14, 30 and 54 (Table 1). Patients treated with SB2 as well as INF also exhibited the lowest progression of

\begin{tabular}{|c|c|c|c|c|c|c|c|c|c|}
\hline \multirow{3}{*}{\multicolumn{2}{|c|}{$\begin{array}{l}\text { Disease activity state } \\
\text { at each visit }\end{array}$}} & \multicolumn{4}{|c|}{ CDAI } & \multicolumn{4}{|c|}{ SDAI } \\
\hline & & \multicolumn{2}{|l|}{ SB2 } & \multicolumn{2}{|l|}{ INF } & \multicolumn{2}{|l|}{ SB2 } & \multicolumn{2}{|l|}{ NF } \\
\hline & & $\begin{array}{c}\text { Radiographic } \\
\text { non-progressors }\end{array}$ & $\begin{array}{c}\text { Mean } \\
\text { change }\end{array}$ & \begin{tabular}{|c|} 
Radiographic \\
non-progressors
\end{tabular} & $\begin{array}{c}\text { Mean } \\
\text { change }\end{array}$ & $\begin{array}{c}\text { Radiographic } \\
\text { non-progressors }\end{array}$ & $\begin{array}{c}\text { Mean } \\
\text { change }\end{array}$ & \begin{tabular}{|c|} 
Radiographic \\
non-progressors
\end{tabular} & \begin{tabular}{|c} 
Mean \\
change
\end{tabular} \\
\hline \multirow{4}{*}{ Week 14} & $\mathrm{HDA}$ & $43 / 62(69.4)$ & 0.44 & $42 / 59(71.2)$ & 0.61 & $25 / 41(61.0)$ & 0.80 & $31 / 45(68.9)$ & 1.03 \\
\hline & IIDA & $64 / 86(74.4)$ & 0.27 & $5782(69.5)$ & 0.64 & $81 / 105(77.1)$ & 0.10 & $63 / 89(70.8)$ & 0.45 \\
\hline & LDA & $43 / 56(76.8)$ & 0.54 & $49 / 58(84.5)$ & -0.38 & $44 / 58(75.9)$ & 0.63 & $53 / 64(82.8)$ & -0.27 \\
\hline & Remission & $7,9(77.8)$ & 0.17 & $68(75.0)$ & 1.44 & $7 / 9(77.8)$ & 0.17 & $79(77.8)$ & 1.00 \\
\hline \multirow{4}{*}{ Week 30} & HDA & $29 / 43(67.4)$ & 0.93 & $33 / 47(70.2)$ & 1.20 & $25 / 37(67.6)$ & 0.79 & $24 / 33(72.7)$ & 1.32 \\
\hline & IDA & $57 / 76(75.0)$ & 0.14 & $49,71(69,0)$ & 0.43 & $59 / 80(73.8)$ & 0.24 & $5884(69.0)$ & 0.54 \\
\hline & LDA & $55 / 4(74.3)$ & 0.40 & $5267(77.6)$ & .0 .10 & $56 / 74(75.7)$ & 0.42 & $54.69(78.3)$ & .0 .23 \\
\hline & Remission & $1620(80.0)$ & 0.05 & $2224(91.7)$ & -0.13 & $17 / 21(81.0)$ & 0.07 & $20 / 22(90.9)$ & 0.07 \\
\hline \multirow{4}{*}{ Week 54} & HDA & $31 / 43(72.1)$ & 0.39 & $25 / 42(59.5)$ & 1.59 & $25 / 36(69,4)$ & 0.65 & $23 / 36(63.9)$ & 1.71 \\
\hline & IDA & $47 / 69(68.1)$ & 0.69 & $4666(69.7)$ & 0.30 & $50 / 73(68.5)$ & 0.57 & $4468(64.7)$ & 0.35 \\
\hline & LDA & $51 / 67(76.1)$ & 0.20 & $6278(79.5)$ & 0.29 & $54 / 69(78.3)$ & 0.18 & $66: 82(80.5)$ & 0.24 \\
\hline & Remission & $2833(84.8)$ & .0 .11 & $23 / 23(100.0)$ & -1.39 & $27 / 33(81.8)$ & .0 .08 & $23 / 23(100.0)$ & -1.22 \\
\hline
\end{tabular}

radiographic damage in remission and the largest progression in HDA, but also very small increases in mTSS in LDA and MDA, in line with previous findings on INF.

Conclusions: The proportion of patients achieving remission or LDA was comparable up to week 54 upon treatment with both SB2 and INF. Inhibition of radiographic progression was also comparable in each disease activity state. The proportion of radiographic non-progressors was also similarly high in patients achieving remission, and overall very low radiographic progression rates were seen even in LDA and MDA in both treatment arms. These data further confirm the comparability of SB2 and INF.

Disclosure of Interest: J. S. Smolen Consultant for: Abbvie, Amgen, AstraZeneca, Astro, Celgene, Glazo, Janssen, Lilly, Medimmune, MSD, NovartisSandoz, Pfizer, Roche, Samsung Bioepis, Sanofi, UCB, J.-Y. Choe Consultant for: Samsung Bioepis, E. Keystone Consultant for: Pfizer, Roche, Janssen, Amgen consultant/Pfizer, Roche, Janssen, Amgen, BMS, Merck. Merck, Celltrion, Samsung Bioepis, Y. H. Rho Employee of: Samsung Bioepis, Y. Lee Employee of: Samsung Bioepis, S. Lee Employee of: Samsung Bioepis DOI: 10.1136/annrheumdis-2017-eular.5524

\section{FRI0188 EFFECTIVENESS OF ADALIMUMAB COMBINATION THERAPY WITH METHOTREXATE AND NON-METHOTREXATE CSDMARDS: RESULTS FROM THE CORRONA RHEUMATOID ARTHRITIS REGISTRY}

D. Pappas ${ }^{1,2}$, J. Griffith ${ }^{3}$, C.A. Schlacher ${ }^{3}$, J.L. Suboticki ${ }^{3}$, R.W. Harrison ${ }^{2}$, Y. Shan ${ }^{2}$, C. Karki ${ }^{2}$, J.M. Kremer ${ }^{4} .{ }^{1}$ Columbia University, New York; ${ }^{2}$ Corrona, LLC, Southborough; ${ }^{3}$ AbbVie, Inc., Abbott Park; ${ }^{4}$ Albany School of Medicine, Albany, United States

Background: Combination therapy of methotrexate (MTX) with biologics results in superior outcomes vs. monotherapy. However, little is known on the effectiveness of adalimumab (ADA) combination therapy with non-MTX conventional synthetic disease modifying anti-rheumatic drugs (CSDMARD).

Objectives: To evaluate whether ADA in combination with non-MTX csDMARD has similar effectiveness as MTX combination therapy on clinical and patient report outcomes (PROs).

Methods: Adult RA patients, naïve to other monoclonal antibodies, who initiated standard dose ADA (40mg q2w) in combination with MTX or $>1$ non-MTX csDMARD between 2003-2016 and had a 6 month follow-up visit were included. The primary outcomes were mean change in clinical disease activity index (CDAl) and mean change in PROs ( $\mathrm{mHAQ}$, pain, fatigue, morning stiffness) from baseline to 6 months. Secondary outcomes included achievement of remission $(\mathrm{CDAl} \leq 2.8)$ /low disease activity (LDA: CDAl $\leq 10)$. Outcomes were evaluated adjusting for covariates that differed at the time of initiation using mixed model linear regression. Kaplan-Meier survival analysis was used to examine the persistency of ADA between the two groups.

Results: A total of 754 patients were included: $\mathrm{N}=519$ ADA+MTX and $\mathrm{N}=235$ ADA+non-MTX csDMARD. Patients on ADA+MTX were slightly younger (mean age: 54.5 vs 57.4 years), with shorter disease duration (median: 3 vs 5 years), more likely to be biologic naïve ( $77 \%$ vs $69 \%$ ) compared to patients on ADA+nonMTX csDMARD (all $p<0.05$ ). Disease activity and PROs were comparable in both groups at the time of initiation (mean CDAl: 20.4 vs 22.8 ; mean pain: 45.3 vs 45.9; mean fatigue: 46.3 vs 47.8 ; mean patient global assessment: 42.8 vs 42.9 (on a VAS $0-100$ ) in ADA+MTX and ADA+nonMTX csDMARD group respectively. Adjusted analysis showed that patients on ADA+MTX had significantly lower mean CDAl at 6 months and higher change in CDAl vs patients in the ADA+non-MTX csDMARD group $(p<0.05)$. In addition, patients on ADA+MTX were more likely to achieve LDA compared to the ADA+non-MTX csDMARD group (Table). Change in PROs and persistency of ADA was comparable in both groups.

Table: Outcomes at 6 months among $A D A+M T X$ and $A D A+$ nonMTX csDMARD therapy

\begin{tabular}{|c|c|c|c|c|}
\hline & $A D A+M T X$ & $\begin{array}{c}\text { ADA + nonMTX } \\
\text { csDMARD }\end{array}$ & Unadjusted ${ }^{b}$ & Adjusted b,c \\
\hline $\begin{array}{l}6 \text { month } \\
\text { outcomes }\end{array}$ & Mean (SD) & Mean (SD) & $\beta(95 \% \mathrm{Cl})$ & $\beta(95 \% \mathrm{Cl})$ \\
\hline $\begin{array}{l}\text { Mean CDAI at } 6 \\
\text { months }\end{array}$ & $11.9(11.5)$ & $15.7(13.1)$ & 4.07 (2.09 to 6.04$)$ & 3.15 (1.11 to 5.18 ) \\
\hline Change in CDAI & $-8.8(13.4)$ & $-7.4(13.4)$ & $1.72(-0.85$ to 4.29$)$ & 3.15 (1.11 to 5.18$)$ \\
\hline Change in $\mathrm{mHAQ}$ & $-0.11(0.39)$ & $-0.1(0.4)$ & $0.01(-0.07$ to 0.08$)$ & $0.01(-0.07$ to 0.08$)$ \\
\hline Change in pain & $-10.1(26.5)$ & $-9.7(30.7)$ & $0.68(-4.51$ to 5.88$)$ & $1.61(-3.58$ to 6.80$)$ \\
\hline \multirow[t]{2}{*}{ Change in fatigue } & $-2.7(25.9)$ & $-5.3(25.1)$ & $-2.64(-9.13$ to 3.84$)$ & \begin{tabular}{|c|}
$-2.58(-9.22$ to 4.07$)$ \\
\end{tabular} \\
\hline & $\begin{array}{c}\text { Response rate } n \\
(\%)\end{array}$ & $\begin{array}{c}\begin{array}{c}\text { Response rate } \\
(\%)\end{array} \\
\end{array}$ & $\begin{array}{l}\text { Odds Ratio }{ }^{+}(95 \% \\
\text { CI) }\end{array}$ & $\begin{array}{c}\text { Odds Ratio"* (95\% } \\
\text { CI) }\end{array}$ \\
\hline $\begin{array}{l}\text { Achievement of } \\
\text { Remission } \\
\text { (CDAls2.8) }\end{array}$ & $46(15.5 \%)$ & $13(8.6 \%)$ & $0.52(0.26,1.06)$ & $0.58(0.27,1.26)$ \\
\hline $\begin{array}{l}\text { Achievement of } \\
\text { LDA (CDAIS10) }\end{array}$ & $136(45.9 \%)$ & $47(31.1 \%)$ & $0.51(0.32,0.80)$ & $0.59(0.37,0.96)$ \\
\hline
\end{tabular}

mHAQ: modified Health Assessment Questionnaire; LDA: Low Disease Activity; nonMTX csDMARD: non-methotrexate conventional synthetic disease modifying anti-rheumatic drug. " Includes leflunomide, sulfasalazine, and hydroxychloroquine.
Compared with MTX combination therapy as a reference; 'Adjustedffor age, duration of RA, work status (part-time, full-time, disabled, retired, other), insurance status (none, private, Medicare), prior biologic count, MTX continuation, baseline CDAI, baseline patient pain.

Conclusions: In this real world study, patients on ADA+MTX had significantly greater improvements in disease activity compared to patients on ADA+nonMTX 
csDMARD therapy but had comparable improvements in PROs at 6 months from initiation.

Acknowledgements: This study is sponsored by Corrona, LLC. The Corrona, LLC. has been supported through contracted subscriptions in the last two years by AbbVie, Amgen, BMS, Crescendo, Eli Lilly and Company, Genentech, GSK, Horizon Pharma USA, Janssen, Momenta Pharmaceuticals, Novartis, Pfizer, Roche and UCB. The design, study conduct, and financial support for the study was provided by AbbVie. AbbVie participated in the interpretation of data, review, and approval of the abstract.

Disclosure of Interest: D. Pappas Grant/research support from: AbbVie, Consultant for: AbbVie, Employee of: Corrona, LLC, J. Griffith Shareholder of: AbbVie, Inc, Employee of: AbbVie, Inc, C. Schlacher Shareholder of: AbbVie, Inc, Employee of: AbbVie, Inc, J. Suboticki Shareholder of: AbbVie, Inc, Employee of: AbbVie, Inc, R. Harrison Employee of: Corrona, LLC, Y. Shan Employee of: Corrona, LLC, C. Karki Employee of: Corrona, LLC, J. Kremer Shareholder of: Corrona, LLC, Grant/research support from: AbbVie, Genentech, Lilly, Novartis, Pfizer, Consultant for: AbbVie, Amgen, BMS, Genentech, Lilly, Regeneron, Sanofi, Pfizer, Employee of: Corrona, LLC

DOI: 10.1136/annrheumdis-2017-eular.1924

\section{FRI0189 SIMILAR EFFICACY AND SAFETY OF BIOSIMILAR CANDIDATE BI 695501 AND ADALIMUMAB ORIGINATOR REFERENCE PRODUCT IN PATIENTS WITH MODERATE TO SEVERE ACTIVE RHEUMATOID ARTHRITIS: 24 WEEK RESULTS FROM A PHASE III CLINICAL STUDY (VOLTAIRE ${ }^{\circledR}$-RA)}

S. Cohen ${ }^{1}$, A. Alonso-Ruiz ${ }^{2}$, P.A. Klimiuk ${ }^{3}$, E. Lee ${ }^{4}$, N. Peter ${ }^{5}$, I. Sonderegger ${ }^{5}$, D. Assudani ${ }^{5} .{ }^{1}$ Metroplex Clinical Research Center, Dallas, United States; ${ }^{2}$ Hospital de Cruces, Barakaldo, Spain; ${ }^{3}$ Medical University of Bialystok and Gabinet Internistyczno-Reumatologiczny, Bialystok, Poland; ${ }^{4}$ Inland

Rheumatology, Upland, United States; ${ }^{5}$ Boehringer Ingelheim, Ingelheim a.R., Germany

Background: PK bioequivalence of BI 695501, a biosimilar candidate, and the adalimumab originator was demonstrated previously (VOLTAIRE ${ }^{\circledR}$-PK: Wynne et al., Expert Opin Investig Drugs 2016;25:1361-70) and led to further clinical development.

Objectives: To demonstrate clinical equivalence of BI 695501 with the adalimumab originator by comparing efficacy, safety and immunogenicity using a clinical model sensitive to detect potential differences between the two biologics. Methods: In this 58-week, multi-national, multicentre, randomised, double-blind, parallel arm Phase III study (NCT02137226), 645 pts (18-80 years) with moderate to severe active RA on stable treatment with methotrexate were randomised to receive US-licensed SC adalimumab originator or BI 695501 40mg Q2W for 24 weeks. At Wk 24, pts on adalimumab originator were re-randomised to continue the adalimumab originator or switch to BI 695501 until Wk 48. Pts on BI 695501 were dummy re-randomised. Co-primary end points were proportion of pts achieving ACR20 at Wks 12 and 24. Equivalence between BI 695501 and the adalimumab originator was demonstrated if the relevant confidence intervals (Cl) for differences in ACR20 response rate at Wks 12 and 24 were within the predefined margins (Wk 12: $90 \% \mathrm{Cl}-12 \%, 15 \%$; Wk 24: $95 \% \mathrm{Cl}-15 \%, 15 \%$ ). The secondary efficacy end point was change from baseline in DAS28-ESR at Wks 12 and 24. Safety and immunogenicity were exploratory objectives. Wk $48 / 58$ data will be reported later.

Results: The co-primary end points of ACR20 response at Wks 12 and 24 were within the pre-defined criteria for equivalence, demonstrating clinical equivalence between $\mathrm{BI} 695501$ and the adalimumab originator (Table 1).

The proportion of pts with treatment-emergent adverse events (TEAE) was similar between the BI 695501 and the adalimumab originator treatment groups (Table 2).

Table 1. Response at Weeks 12 and 24

\begin{tabular}{|c|c|c|c|c|}
\hline \multirow[t]{2}{*}{ ACR, \% } & \multicolumn{2}{|c|}{ Week 12} & \multicolumn{2}{|c|}{ Week 24} \\
\hline & $\begin{array}{c}\text { BI } 695501 \\
n=321\end{array}$ & $\begin{array}{c}\text { Adalimumab } \\
\text { originator } \\
\mathrm{n}=318\end{array}$ & $\begin{array}{c}\text { BI } 695501 \\
n=321\end{array}$ & $\begin{array}{c}\text { Adalimumab } \\
\text { originator } \\
n=318\end{array}$ \\
\hline ACR20* & 67.0 & 61.1 & 69.0 & 64.5 \\
\hline ACR50 & 29.3 & 31.0 & 36.8 & 36.8 \\
\hline ACR70 & 10.1 & 11.1 & 13.6 & 18.2 \\
\hline $\begin{array}{l}\text { DAS28-ESR } \text {, mean change } \\
\text { from baseline }(95 \% \mathrm{Cl})\end{array}$ & $\begin{array}{c}-2.1 \\
(-2.28,-2.01)\end{array}$ & $\begin{array}{c}-2.0 \\
(-2.18,-1.91)\end{array}$ & $\begin{array}{c}-2.4 \\
(-2.51,-2.21)\end{array}$ & $\begin{array}{c}-2.4 \\
(-2.54,-2.24)\end{array}$ \\
\hline
\end{tabular}

*Week 12 risk difference (RD) and $90 \% \mathrm{Cl}$ for $\mathrm{Bl} 695501$-adalimumab originator are $5.9 \%$ and $90 \% \mathrm{Cl}(-0.9 \%, 12.7 \%)$; \# Week $24: \mathrm{RD}$ and $95 \% \mathrm{Cl}$ are $4.5 \%$ and $(-3.4 \%, 12.5 \%)$.

Table 2. Overview of TEAEs up to Week 24

\begin{tabular}{lcc}
\hline Pts, $n(\%)$ & BI $695501(n=324)$ & Adalimumab originator $(n=321)$ \\
\hline$\geq 1$ TEAE & $138(42.6)$ & $148(46.1)$ \\
$\geq 1$ TEAE related to trial drug & $36(11.1)$ & $44(13.7)$ \\
$\geq 1$ Non-serious TEAE & $135(41.7)$ & $141(43.9)$ \\
$\geq 1$ serious TEAE & $12(3.7)$ & $18(5.6)$ \\
$\geq 1$ serious TEAE related to trial drug & $1(0.3)$ & $5(1.6)$ \\
A TEAE leading to trial drug discontinuation & $8(2.5)$ & $11(3.4)$ \\
A TEAE leading to death & $0(0.0)$ & $0(0.0)$ \\
\hline
\end{tabular}

Rates of serious AEs and discontinuation due to TEAEs were similar across the groups. No deaths were reported during the study. Similar frequencies of pts tested positive for anti-drug antibodies (BI 695501 43.2\%; adalimumab originator 47.8\%), and neutralising antibodies (BI 695501 16.0\%; adalimumab originator $20.6 \%$ ) in both groups at Week 24.

Conclusions: This study in pts with RA demonstrated that BI 695501 and the adalimumab originator are highly similar in terms of efficacy, safety and immunogenicity. Disclosure of Interest: S. Cohen Grant/research support from: Amgen, Boehringher Ingelheim, Coherus, Pfizer, Consultant for: Amgen, Boehringher Ingelheim, Celltrion, Merck, Pfizer, Sandoz, A. Alonso-Ruiz: None declared, P. Klimiuk: None declared, E. Lee: None declared, N. Peter Employee of: Boehringer Ingelheim, I. Sonderegger Employee of: Boehringer Ingelheim, D. Assudani Employee of: Boehringer Ingelheim

DOI: 10.1136/annrheumdis-2017-eular.3405

\section{FRI0190 CLINICAL OUTCOMES FROM A NATIONWIDE NON-MEDICAL SWITCH FROM ORIGINATOR TO BIOSIMILAR ETANERCEPT IN PATIENTS WITH INFLAMMATORY ARTHRITIS AFTER 5 MONTHS FOLLOW-UP. RESULTS FROM THE DANBIO REGISTRY}

B. Glintborg, I.J. Sørensen, A.G. Loft, J. Esbesen, H. Lindegaard, D.V. Jensen,

K. Danebod, S. Dieperink, O. Hendricks, I.M.J. Hansen, A. Linauskas,

S. Kristensen, L.S. Andersen, M. Hossein, H. Nordin, B.L. Andersen,

S. Chrysidis, J.L. Raun, N. Manilo, J. Grydehøj, E.B. Dalgaard, D.D. Pedersen,

N.S. Krogh, M.L. Hetland. The DANBIO registry and the Danish Departments of Rheumatology, Copenhagen, Denmark

Background: In Denmark, biological drugs are provided free by the hospitals to the patients via a tax-based system. In 2015 a non-medical switch from originator infliximab to CT-P13 was conducted (1). According to national guidelines in April 2016, a non-medical switch from originator (ETA, Enbre ${ }^{\circledR} 50 \mathrm{mg} /$ week) to biosimilar etanercept (SB4, Benepali ${ }^{\circledR}$ ) was dictated when SB4 was marketed, including patients with inflammatory rheumatic diseases treated in routine care. Objectives: To investigate 3 months' disease activity and 5 months' treatment withdrawal in ETA-treated patients (pts) with rheumatoid arthritis (RA), psoriatic arthritis (PsA) and axial spondyloarthrits (SpA), who were switched to SB4 and monitored prospectively in the DANBIO registry.

Methods: Pts with RA/PsA/SpA followed in DANBIO since start of first bDMARD were included. Disease activity at 3 months before switch (pre-switch), at the switch and after 3 months (post-switch) and changes over time ( $\Delta$ pre-switch and $\triangle$ post-switch) were calculated. Disease flare was defined as $\triangle D A S 28 \geq 1.2$ (RA/PsA) or $\triangle \mathrm{ASDAS} \geq 1.3(\mathrm{SpA})$. Factors associated with withdrawal (gender/ age/diagnosis/bDMARD-treatment-no/comedication methotrexate/baseline CRP/ patient's global score) were explored by multivariable Cox regression analysis. Results: In total, 1548 switch pts were identified (891 RA, 335 PsA, 322 SpA). $60 \%$ were women, age (median (IQR) 56 (44-65) yrs)). Prior ETA treatment duration was $5.2(3.2-8.0)$ yrs. ETA was the first biological treatment in $49 \%$, and the second in $33 \%$ of pts. Concomitant MTX was given in $60 \%(\mathrm{RA}) / 49 \%$ (PsA) $/ 15 \%$ (SpA). Median follow-up time was 154 (110-178) days.

Disease activity remained largely unchanged 3 months prior to vs. after the switch (Table). The proportion of patients with disease flare pre-/post switch was $8 \% / 13 \%$ (RA), $9 \% / 13 \%$ (PsA), $5 \% / 5 \%$ (SpA).

Overall, 129 pts (9\%) stopped SB4 treatment during 5 months' follow-up (Table). Prior ETA treatment duration in these patients was $4.5(2.7-7.1)$ years.

Higher patient's global score (HR $1.12 / \mathrm{cm}, 95 \% \mathrm{Cl}(1.05-1.21), \mathrm{p}=0.002)$ and no concomitant methotrexate (HR $2.28(1.48-3.52), p<0.001)$ at baseline were associated with withdrawal.

\begin{tabular}{|c|c|c|c|c|c|c|}
\hline & \multicolumn{3}{|c|}{ Disease activity, median(IQR) } & \multicolumn{2}{|c|}{ Changes, median(IQR) } & \multirow[t]{2}{*}{ P* } \\
\hline & pre-switch & switch & post-switch & $\Delta$ pre-switch & $\Delta$ post-switch & \\
\hline \multicolumn{7}{|l|}{$R A, n=891$} \\
\hline DAS28 & $2.1(1.7-2.9)$ & $2.1(1.6-2.9)$ & $2.2(1.6-3.1)$ & $0.0(-0.4-0.5)$ & $0.0(-0.4-0.5)$ & 0.2 \\
\hline $\mathrm{HAQ}$ & $0.6(0.2-1.3)$ & $0.8(0.1-1.3)$ & $0.8(0.3-1.3)$ & $0.0(-0.1-0.1)$ & $0.0(-0.1-0.1)$ & 0.7 \\
\hline CRP, mg/l & $3(1-7)$ & $2(1-6)$ & $3(1-6)$ & $0(-2-1)$ & $0(-1-1)$ & 0.02 \\
\hline VAS global, mm & $30(13-57)$ & $28(13-55)$ & $31(11-62)$ & $0(-11-9)$ & $0(-9-11)$ & 0.1 \\
\hline \multicolumn{7}{|l|}{ PsA, $n=335$} \\
\hline DAS28 & $2.0(1.5-2.6)$ & $2.0(1.6-2.8)$ & $2.1(1.5-3.0)$ & $0.0(-0.2-0.5)$ & $0.0(-0.6-0.5)$ & 0.7 \\
\hline $\mathrm{HAQ}$ & $0.5(0.1-1.1)$ & $0.5(0.0-1.1)$ & $0.5(0.1-1.1)$ & $0.0(-0.1-0.1)$ & $0.0(-0.1-0.1)$ & 0.7 \\
\hline CRP, $\mathrm{mg} / \mathrm{l}$ & $2(1-4)$ & $2(1-4)$ & $2(1-4)$ & $0(-2-1)$ & $0(-1-1)$ & 0.04 \\
\hline VAS global, mm & $31(12-58)$ & $30(13-54)$ & $32(13-59)$ & $0(-9-7)$ & $0(-7-12)$ & 0.2 \\
\hline \multicolumn{7}{|l|}{$S p A, n=322$} \\
\hline BASDAl, $\mathrm{mm}$ & $33(15-51)$ & $27(12-48)$ & $29(16-47)$ & $-1(-7-5)$ & $1(-5-8)$ & 0.03 \\
\hline CRP, mg/l & $3(1-6)$ & $3(1-5)$ & $3(1-5)$ & $0(-2-1)$ & $0(-1-1)$ & 0.4 \\
\hline VAS global, $\mathrm{mm}$ & $34(16-59)$ & $30(12-53)$ & $31(15-53)$ & $-1(-12-6)$ & $2(-6-14)$ & 0.04 \\
\hline ASDAS & $2.0(1.3-2.8)$ & $1.9(1.2-2.7)$ & $1.9(1.3-2.7)$ & $-0.1(-0.4-0.2)$ & $0.1(-0.4-0.5)$ & 0.1 \\
\hline \multicolumn{7}{|c|}{ Reasons for withdrawal during $\approx 5$ months follow-up ( $n=129$ ) } \\
\hline $\begin{array}{l}\text { Lack of effect } 59 \\
\text { death } 1 \text {, other/u }\end{array}$ & verse everio & 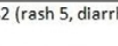 & . & 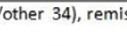 & $v^{2}$ & \\
\hline
\end{tabular}

Conclusions: In 1548 patients with inflammatory rheumatic diseases treated with ETA for $>5$ years, disease activity was largely unaffected in the majority of patients 3 months after non-medical switch to SB4 and comparable to the fluctuations observed in the 3 months prior to the switch. Several patients $(\approx 9 \%)$ 